\title{
Integrated approach to providing for environmental friendliness and safety of the technological processes
}

\author{
Leonid Shvartsburg ${ }^{1, *}$, Olga Yagolnitser $^{1}$, and Elena Butrimova ${ }^{1}$ \\ ${ }^{1}$ MSTU “STANKIN", department "Engineering Ecology and Life safety”, 127055, Vadkovsky lane, \\ 3a, Moscow, Russia
}

\begin{abstract}
Basing on energy-related analysis, the article discusses the issues of creating integrated approaches to providing for environmental friendliness and safety of the technological processes of form-shaping and the methodology of quantitative evaluation of ecological effectiveness of these processes. Energy-related analysis allows to find the interrelations between energy efficiency and environmental friendliness of technological processes, to create a joint methodology for improving these indices by reducing energy losses and compensating the "underload" of electric motors of processing equipment. The established interrelations allowed to compose the integrated ecological quality index, making possible to estimate numerically the environmental friendliness and safety of technological processes for each particular implementation. As an example, the article presents the formation of a comprehensive criterion for environmentally justified selection of LCTA and systems for LCTA application as one of the possible approaches to detailing of environmental friendliness and safety of technological processes based on rational choice of LCTA.
\end{abstract}

\section{Problem definition}

The problem of providing for environmental friendliness and safety of technological processes is the most important from the point of view of ensuring their quality indices and competitiveness [1].

Considering the special features of the implementation of technological processes, the issues of environmental friendliness and safety, of minimizing the impact on the environment and on humans are mainly solved by evaluating the individual components of this impact. However, it is important, and in many cases sufficient, to evaluate the comprehensive (integrated) impact without analyzing the individual components, such as vibration and noise, air pollutants, thermal pollutants, etc. [2-6]

Evaluation of integrated impact will allow not only to determine the impact of technological processes on the environment and humans, but also to compare in regard of

\footnotetext{
*Corresponding author: lesh@stankin.ru
} 
environmental friendliness and safety the technological processes of different types, the processes implemented on different types of technological equipment.

From the point of view of the problem being solved, very important is also the numerical evaluation of environmental friendliness and safety of technological processes. This will allow not only to quantify these quality indices, but also to outline the ways for reducing the impact of technological processes on the environment and improving their safety for humans.

\section{Analysis of recent achievements}

Currently, two criteria are used for integrated evaluation of environmental friendliness and safety - the environmental indices [7] and environmental risks [8]. Despite the differences between them, both criteria imply a common approach to integrated evaluation - statistical approach. In the first case, the environmental index is formed on the basis of aggregate statistical data evaluating the environmental friendliness and safety for each type of economic activity. In the second case, the environmental risk is formed on the basis of multiplying three probabilities - the probability of occurrence of a negative event, the probability of its impact on the object, and the probability that this impact will cause negative consequences.

However, neither of these types of integrated evaluation of environmental friendliness and safety allows evaluating the particular implementation of the technological process taking into consideration the conditions of implementation, process parameters, the state of technological equipment and tools and other factors affecting the impact of the technological process on the environment and on humans.

Besides, it is important to create a joint methodology for integrated evaluation of environmental friendliness and safety of each implementation of technological processes, considering all the diversity of the types of technological processes, modes and conditions of implementation, the diversity of equipment on which these processes are implemented [9-11].

\section{Purpose and objectives of the work}

The purpose of the work is the creation of a joint methodology for evaluation of environmental friendliness and safety of technological processes, first of all - of formshaping, for each particular implementation, considering all the diversity of the types of technological processes, modes and conditions of implementation, the diversity of equipment on which these processes are implemented.

Objectives of the work:

1) analyzing the technological process of form-shaping as two energy-related processes - the process of converting electrical energy into mechanical energy performed in the electrical systems of the equipment, and the process of transfer of mechanical energy to the processing zone performed by the kinematics of the technological equipment;

2) comprising the energy balance of technological processes and demonstrating that energy losses during energy conversion and transfer, as well as excessive consumption of current due to "underload" of technological equipment are the causes of worsening of environmental friendliness and safety of technological processes;

3) forming, on the basis of energy balance, the integrated environmental quality index of the technological processes; analyzing this index from the point of view of 
minimization of the impact of technological processes on the environment and on humans;

4) as an example, forming a comprehensive criterion for evaluating the options of environmentally friendly selection of LCTA.

\section{Main part}

Let us represent the technological process of form-shaping as two energy-related processes - the process of converting electrical energy into mechanical energy performed in the electrical systems of the equipment, and the process of transfer of mechanical energy to the processing zone performed by the kinematics of the technological equipment. In this case, the energy diagram of this process may be represented as shown in figure 1 [12].

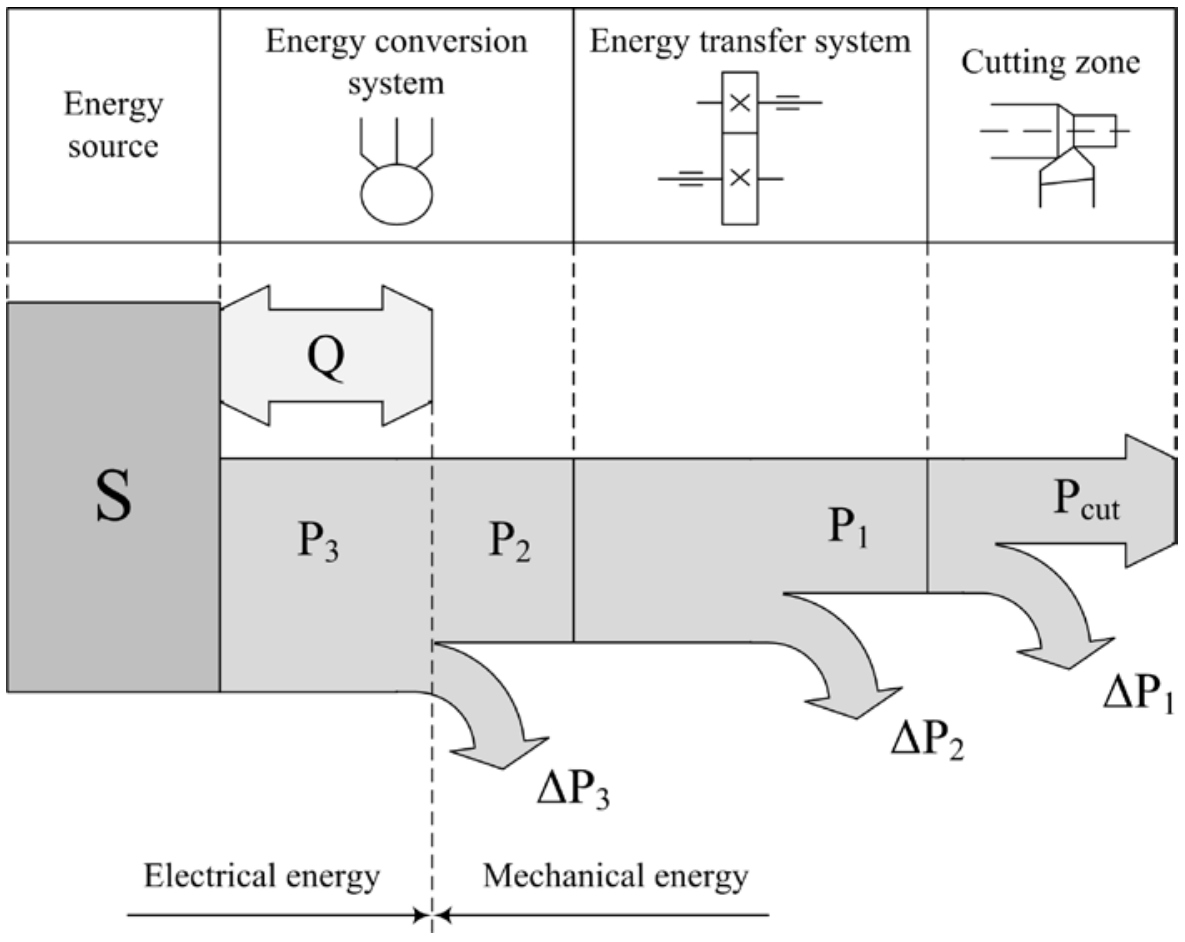

Fig. 1. Energy diagram of form-shaping process: $\mathrm{S}$ - consumed power; $\mathrm{Q}$ - reactive component of consumed power; $\mathrm{P}_{1}, \mathrm{P}_{2}, \mathrm{P}_{3}$ - active components of consumed power; $\mathrm{P}_{\text {cut }}-$ cutting power; $\Delta \mathrm{P}_{1}-$ losses in the processing zone; $\Delta \mathrm{P}_{2}-$ losses in course of transfer of mechanical energy; $\Delta \mathrm{P}_{3}-$ losses in course of conversion of electrical energy into mechanical energy.

In this case, all types of losses and the power factor $\cos \varphi$ comprise the negative impact of technological processes of form-shaping on the environment and on humans [13], and the energy balance may be represented as:

$$
S=\frac{P_{c u t}+\sum_{i=1}^{3} \Delta P_{i}}{\cos \varphi}
$$

Taking into account that $P_{\text {cut }}$ is determined by the technologist and remains constant for the particular implementation of the technological process, the integrated evaluation of the 
impact of the particular implementation of the technological process on the environment and on humans is determined by the expression:

$$
I=\frac{P_{c u t}}{S}=\frac{P_{c u t}}{P_{c u t}+\sum_{i=1}^{3} \Delta P_{i}} \cdot \cos \varphi
$$

This value should be named the integral environmental quality index of each particular implementation of the technological process of form-shaping [14-16].

It follows from the last expression that in order to reduce the impact of the technological process on the environment and on humans, it is necessary to reduce $\Delta P_{i}$ or increase the power factor $\cos \varphi$. The practical implementation of these two ways for increase of $I$ is analyzed in detail in $[13,16]$.

It should be noted that increasing the integral index value by reducing energy losses allows to analyze and minimize the particular impacts on the environment and on humans.

For example, the mechanical energy losses in the processing zone cause considerable heat wastes due to conversion of mechanical energy into heat energy. This results in degradation of quality of the surface layer of the products, increased tool wear. To minimize these effects, the lubricating-cooling technological agents (LCTA) are used which provide lubricating, cooling, dispersing action directly affecting the value of mechanical losses in the processing zone. However, the products of thermal destruction of applied LCTA cause air pollution in the working area. To ensure maximum effect of LCTA usage with simultaneous decrease of negative consequences of LCTA usage for the production staff and the environment, the comprehensive criterion was formed for evaluation of environmentally justified selection of LCTA.

Based on the developed LCTA database containing the parameters of LCTA and of systems for LCTA application, the information retrieval system (IRS) "ECO LCTA" was created for environmentally justified LCTA selection [17].

In accordance with the developed selection algorithm (fig. 2), based on the user-defined restrictions (block 1) on search parameters and application of restrictions (block 2), a certain subset of solution options $\Omega^{*}=\left\{\omega_{1}, \ldots, \omega_{\mathrm{k}}\right\}, k \leq n$ is picked from the overall set of initial options $\Omega=\left\{\omega_{1}, \ldots, \omega_{\mathrm{n}}\right\}$ (block 3 ). Further search is performed over this subset by evaluating the selection options using the comprehensive criterion (block 4). The evaluation is performed within the framework of this algorithm by technological, environmental and economic parameters of the technological system that uses LCTA. If the selected option does not satisfy the user, the decision-making process is resumed with new, updated or changed parameters until the final result is obtained.

The comprehensive criterion is formed considering the specified restrictions on the relations and the requirements to LCTA parameters. It is a collection of parameters and characteristics of LCTA and of the systems for LCTA application, and may be changed during query generation depending on the user-defined significance of these parameters. The comprehensive criterion includes technological, environmental and economic parameters of the technological system with the use of LCTA [18]. In particular, the blocks of parameters of the comprehensive criterion were formed characterizing toxicity of LCTA and of the products of LCTA thermal destruction, and also energy consumption and formation of energy wastes (thermal wastes, vibration wastes, etc.) in the technological processes with application of LCTA.

The presented algorithm served as the basis for development of the methodology for selection of LCTA and systems of LCTA application using the comprehensive criterion $[18,19]$. 


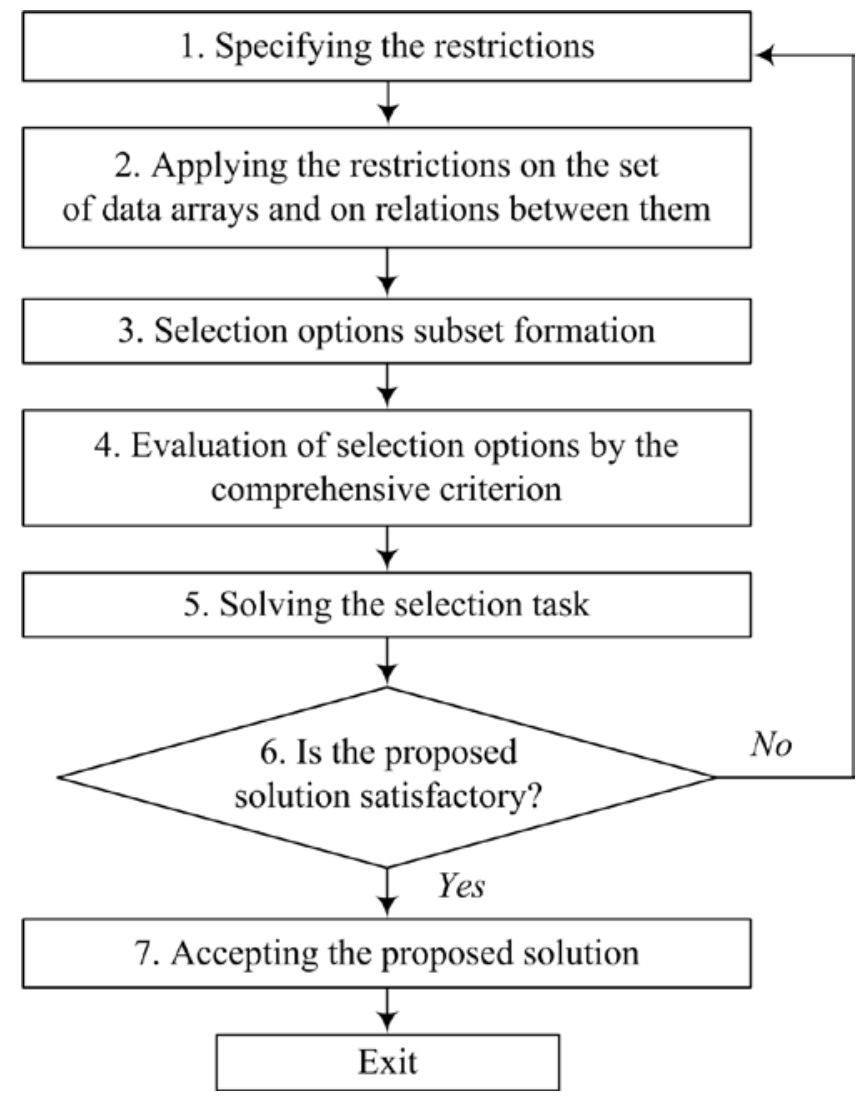

Fig. 2. Schematic algorithm for selection of LCTA and systems for LCTA application.

\section{Conclusions}

1. Basing on energy-related analysis of the technological process and its representation in the form of two processes - the process of converting electrical energy into mechanical energy and the process of transfer of mechanical energy to the processing zone, the unified methodology for evaluating the environmental friendliness and safety of these processes was developed based on the ratio of cutting power to consumed power.

2. The developed methodology makes it possible to quantify the impact of each particular implementation of technological processes of form-shaping on the environment and on humans, taking into consideration all the diversity of types of technological processes, modes and conditions of their implementation, the diversity of equipment on which these processes are implemented. Besides, this methodology allows to compare the different technological processes in each particular implementation in regard of their environmental friendliness and safety.

3. The developed methodology makes it possible to form the main ways of reducing the impact of a particular implementation of technological processes on the environment and on humans by reducing energy losses during energy conversion and transfer to the processing zone, and by increasing the power factor.

4. Further decrease of the impact of technological processes on the environment and on humans for each particular index should be performed by converting the energy losses into 
a specific type of pollutant, as demonstrated on the basis of a comprehensive criterion of environmentally justified selection of LCTA.

5. Further study in this field relates to establishing qualitative and quantitative interrelations between energy losses and particular types of pollutants.

\section{References}

1. L.E. Shvartsburg, T. Zaborovski, P. Cyplik, Log Forum, 13(4), 495-506 (2017)

2. N.A. Ivanova, S.A. Ryabov, L.E. Shvartsburg, Russian Engineering Research, 36, 3, 235-238 (2016)

3. Yu.V. Golubkov, N.V. Ermolaeva, L.E. Shvartsburg, Chemistry and Technology of Fuels and Oils, 52, 1, 1-5 (2016)

4. L.E. Shvartsburg, N.A. Ivanova, S.A. Ryabov, T. Zaborovski, Life Science Journal, 11 (10s), 228-230 (2014)

5. S.I. Gvozdkova, L.E. Shvartsburg, Procedia Engineering, 206, 958-964 (2017)

6. P.E. Rodriguez, L.E. Shvartsburg, M.S. Artemyeva, Procedia Engineering, 206, 588593 (2017)

7. J.C. Kurtz, L.E. Jackson, W.S. Fisher, Ecological Indicators, 1, 1, 49-60 (2001)

8. S.A. Medvedeva, 21st century. Technosphere safety, 1, 1(1), 67-81 (2016)

9. S.B. Egorov, A.V. Kapitanov, V.G. Mitrofanov, L.E. Shvartsburg, N.A. Ivanova, S.A. Ryabov, Mathematics Education 11, 7, 2213-2225 (2016)

10. T. Zaborovski, L.E. Shvartsburg, S.G. Konov, Materials Science Forum, 876, 69-73 (2016)

11. A.V. Kapitanov, V.G. Mitrofanov, I.S. Omel'chenko, O.S. Sirotkin, Journal of Machinery Manufacture and Reliability, 44, 7, 646-649 (2015)

12. L.E. Shvartsburg, Ecology and industry of Russia, 3, 4-9 (2015)

13. L.E. Shvartsburg, E.V. Butrimova, O.V. Yagolnitser, Procedia Engineering, 206, 10091014 (2017)

14. S.B. Egorov, A.V. Kapitanov, V.G. Mitrofanov, L.E. Shvartsburg, N.A. Ivanova, S.A. Ryabov, International Journal of Environmental and Science Education 11, 11, 4065 4078 (2016)

15. N.A. Ivanova, S.A. Ryabov, L.E. Shvartsburg, Bulletin of Machine Building, 9, 36-38 (2015)

16. L.E. Shvartsburg, E.V. Butrimova, O.V. Yagolnitser, MATEC Web of Conferences, 129, 01027 (2017)

17. M.Y. Hudoshina, O.V. Butrimova, Vestnik MSTU «STANKIN», 3, 45-51 (2008)

18. M.Y. Hudoshina, O.V. Butrimova, Ecology and Industry of Russia, 19(5), 46-49 (2015)

19. M.Y. Hudoshina, O.V. Butrimova, Hearald of the Moscow university of finances and law MFUA, 1, 149-154 (2012) 